\title{
Pregnant mothers' knowledge, attitude and practice towards preventions of iron deficiency anemia in Harar Town, Ethiopia
}

\author{
Abdu Oumer ${ }^{1}$, Arif Hussein ${ }^{2}$ \\ ${ }^{1}$ College of Health Sciences and Medicine, Department of Public Health, University, Ethiopia \\ ${ }^{2}$ Department of Nursing, Harar Health Science College, Ethiopia
}

\begin{tabular}{l} 
Article Info \\
\hline Article history: \\
Received Mar 14, 2019 \\
Revised Apr 19, 2019 \\
Accepted May 13, 2019
\end{tabular}

Keywords:

Attitude

Iron Deficiency Anemia (IDA)

Knowledge

Practices

Prevention

\begin{abstract}
Low maternal risk perception, poor dietary practice and low adherence to iron and folate tablets among pregnant women are major contributors for higher burden of anemia. Iron deficiency anemia contribute to more than half of Anemia among pregnant women. Thus the level of maternal awareness and attitude towards dietary and other prevention practices of anemia are not well established in the study area. This study was to assess knowledge, attitude and practice of pregnant mothers towards the prevention of iron deficiency anemia in Ethiopia, 2018. Hospital based Cross sectionals study was conducted on randomly selected, 128 pregnant mothers attending antenatal care service in Harar town. Data were collected by health professionals using pre tested questionnaire containing socio demographic, knowledge, attitude and practice related questions. Attitude questions were organized in five Likert scale from strongly disagree to strongly agree using positive statements. Similarly, practices were assessed in yes/no (appropriate practices were scored as yes or no otherwise). Data was analyzed using SPSS version 20 using frequency, tables, graphs and means. Pearson correlation with $r$ was used to assess the relationship between knowledge, attitude and practice. Analysis of Variance was used to compare the mean practice by different factors. Knowledge, attitude and practice of pregnant women on preventions of IDA are not satisfactory. Thus poor practice towards prevention of IDA is the main contributing factor for high burden of anemia.
\end{abstract}

Copyright (C) 2019 Institute of Advanced Engineering and Science. All rights reserved.

\author{
Corresponding Author: \\ Abdu Oumer, \\ Lecturer, Ethiopia, \\ Department of Public Health, \\ University, Ethiopia. \\ Email: phnabu@gmail.com
}

\section{INTRODUCTION}

Anemia is a condition in which human body don't have enough healthy red blood cells to carry adequate oxygen to the body's tissues which may be caused by numerous nutritional and other causes. According to World Health organization (WHO) definition of Anemia is "a pathologic situation in which the Red Blood Cell mass (RBCs) or its oxygen-carrying capacity is inadequate to meet physiologic demands of the body. This problem in pregnants is identified by using hemoglobin cuts off point below 11g/dl [1-2]. Anemia is considered as top major health problem worldwide. Globally, more than one thirds of world population are victims of anemia. Anemia is common health related problem worldwide with great burden in low and mile income countries in children and adults. An estimated, $43 \%$ and $9 \%$ of world population is affected by anemia in developing and western countries, respectively [3].

Nutrition is a fundamental pillar for the human being, for the health and development of entire life [4-6]. Now a days for both developed and developing country malnutrition is the great problem globally, more specifically under-nutrition and micronutrient deficiencies are widespread problems in developing 
countries [7-8]. Malnutrition during this periods of life is associated with poor maternal health and different poor neonatal and adulthood chronic illness risks. Thus micronutrient deficiencies during the first 1,000 days of life are associated with poor maternal health and neonatal outcomes like morbidity, mortality, cognitive loss and congenital deformities. Low birth weight from anemia and other causes accounts more than 800,000 deaths each year in neonatal death [9-10].

Pregnancy is a period of significant increase in iron requirement; the demand for iron is higher a result of numerous maternal adaptations like increase in number of red blood cell and higher needs for iron by developing and growing organs, placenta and fetus [6]. Iron is needed in significant amount to support maternal and fetal growth. Despite increased iron requirements, pregnancy is also a period of increased risk for anemia which is higher than in non-pregnant state [5, 11]. Iron Deficiency Anemia (IDA) among pregnant have a potential to cause cognitive decline, increased prevalence of underweight children and higher early neonatal and infant mortality [12].

Among the main causes of anemia, inadequate iron intake or higher iron loss are the predominant one accounting for above $50 \%$ of cases. Especially in low income countries where about $38 \%$ of pregnant women had iron depletion, it has even greater share in anemia causation [13]. Out of the total global burden of anemia, over 40 million are pregnant women are anemic, in which IDA account for $75 \%-95 \%$ of cases [1,6]. But the majority of pregnant mothers lack correct perception [14]. As global effort to achieve the sustainable development goals, as one of the strategic objective awareness raising has got a great deal especially with invisible forms of malnutrition like anemia. In 2018, an estimated 264 million women are were victims of IDA. With the current global effort to eliminate the current global malnutrition by 2025 , IDA is one of the great Nutritional concern worldwide [15].

Worldwide estimates of IDA showed the prevalence of anemia in Africa, reaches up to $52 \%$. Thus about $18 \%$ and $52 \%$ of population was affected in developed and developing countries respectively. Globally, about 29.4 women were affected by anemia while, magnitude of $38.2 \%$ (32.4 million pregnant women) was reported among pregnant. [16]. Even though the burden of anemia among pregnant mothers has declined from $43 \%$ to $38 \%$ over the past decades, it still showed that the world Health Assembly (WHA) target of 50\% (as compared to 12\%), reduction of anemia by 2025 is far and countries need to focus on achieving this target in near future [6].

In Ethiopia, about $17 \%$ of women in reproductive age group had anemia, while about $22 \%$ of pregnant were anemic [17]. Additionally, magnitudeof anemia varies as $27.9 \%$ in southeast Ethiopia [15] and 39.4\% in southern Ethiopia [18]. Higher burden of anemia is reported in different parts of Ethiopia [19-21]. Lack of awareness, poor dietary practice and inappropriate dietary counselling of pregnant mothers are major contributors to the high burden of anemia. Additionally, it is evident that only $72 \%$ of mothers are aware of anemia. Anemia is also a severe public health important problem in Ethiopia in which greater than $40 \%$ of pregnant women were anemic [17].

Despite anemia have been major public health problem for decades, no promising movements has been observed towards reducing anemia burden by half, still anemia is high globally [1]. Strategies for the reduction and control of anemia in vulnerable groups as women is one of the priority agendas globally [2]. In addition, improving the knowledge, attitude and dietary practice of the mothers through dietary diversification, fortification (Iron and other supplements) are important nutrition specific interventions to alleviate anemia [10]. Therefore, the aim of this particula survey was to assess knowledge, attitude and practice of Pregnant mothers attending Antenatal Care (ANC) on prevention and control of IDA. This study will give baseline evidence on the level of maternal awareness and intention to practice good dietary practices among pregnant. Thus, it will be valuable input for targeted behavioral interventions at community or facility level in order to improve the hemoglobin level and overall health of pregnant.

\section{RESEARCH METHOD}

\subsection{Study setting}

Hospital based survey was employed in Harar town, Harari region, Eastern Ethiopia with total population of 250,903 in 2018 . Out of these, 139,200 (60\%) resides in urban while 116,928 are males with estimated 64,939 were in reproductive age groups. The region is composed of 9 districts with 19 urban and 17 rural Kebeles [22]. According to Harari Health Bureau reported in 2015 Harari region health coverage was estimated to be $100 \%$. There are three public hospitals, two private hospital, eight health centers, 20 health posts and about 18 private clinics in the region. There were an estimated 7169 pregnant women in the region.

\subsection{Sample size determination}

The sample size was estimated by using population proportion formula using the prevalence estimate of good knowledge (p1), attitude (p2) and practice (p3) from previous studies. Thus taking knowledge towards

Pregnant mothers' knowledge, attitude and practice towards preventions of iron deficiency... (Abdu Oumer) 
nutritional anemia among pregnant women (P1), as 69\% had good knowledge about prevention of IDA [23], margin of error $(5 \%), z \alpha / 2$ the critical value with $95 \%$ confidence level as 1.96 , the minimum sample size became 329. Similarly using attitude towards nutritional anemia among pregnant women $(\mathrm{P} 2=82.2 \%)$ and 59.5\% ANC attending women were following good practices to prevent anemia in pregnancy [23], the sample size goes 73 and 372 respectively. Since the expected monthly flow of antenatal mothers were below the stated sample size, thus using the finite population correction the final sample size became 128 .

\subsection{Sampling technique/ procedures}

The total sample size was proportionally allocated to Hiwot Fana specialized University Hospital and Jugol Hospital. Jugol Hospital with an average monthly flow of pregnant mothers $(n=70)$ and Hiwot Fana specialized university Hospital $(n=116)$. Thus 48 and 80 clients were selected from Jugol and Hiwot Fana specialized university Hospital respectively.

\subsection{Data collection methods}

Data were collected using pre prepared structured questionnaire, containing socio-demographic, knowledge related, attitude and practice related questions on prevention of IDA among pregnant women. The tool was prepared by English version and translated into the local language by trained nurse professionals. A sets of questions were adapted from previous studies and literatures was used to assess knowledge, attitude and practice towards IDA. One day supportive training, close supervision and daily checkup of the collected data was done to improve the quality of data. The collected data were entered in computer software and checked for consistency and outliers before analysis.

\subsection{Methods of data analysis}

SPSS version 20 was used to process and analyze the data. The data were presented using frequency, percentage, table and graph. In addition the knowledge, attitude and practice score was done by using the compute command. The knowledge, attitude and practice score were categorized in to good versus poor knowledge and practice and positive versus negative attitude using the mean score as cut off point. Thus one way analysis of variance was done with $F$ statistics and $p$ value. Association at $p$ value below 0.05 was used to declare statistically significant difference in mean practice level of the mothers.

\subsection{Ethical consideration}

Before actual field work, formal ethical clearance was issued by ethical review committee from Harar Health Science College. Respondent's willingness to participate in the study was obtained verbally with an honest explanation of the objectives of the study. No personal identifiers were collected from the respondents.

\section{RESULTS AND DISCUSSION}

This study assessed the knowledge, attitude and practice towards a prevention method of IDA. In this study, awareness related to cause of anemia most had known poor nutrition, bleeding during pregnancy and multiple pregnancy as cause for IDA. A similar study done in Palestine [25], inadequate nutrition, including not having a balanced diet containing protein-rich foods, not consuming iron supplements and the presence of malaria were reported as the main cause of anemia. But study in another part [14] showed that only $3 \%$ of mothers elicited iron deficiency as a cause of anemia. While similar study [11] showed that malaria is main cause of anemia. In another study [26] showed more than half, (68.1\%) recognized lack of iron in food as the cause for anemia.

But our study also showed a poor awareness level $(31.3 \%)$ on the role of Iron in causing anemia. Thus, as more than half of anemia is attributed to Iron deficiency, mothers had poor knowledge of the major cause of anemia [1]. This difference can be due to the difference in socioeconomic level of participants and the quality of health care (ANC) given in the two countries. This emphasizes the need for better integration and implementation of counselling schedules with each visit. Awareness level towards IDA is above average (88.1\%) which is similar in a study done Sierra Leone [26] shows $99 \%$ had heard about anemia. While 58.6\% of mothers were found to be aware of prevention of IDA. Almost half of mothers are not aware that the role of fibers, coffee and tea after meals in decreasing the fractional absorption iron by almost $70 \%$ responded negatively. There is a need for focused and simple counselling by health professionals (specifically ANC care givers) on the causes and managements of IDA.

Despite this scientific fact, almost $46 \%$ of pregnant reported to have a habit of drinking coffee or tea immediately after meals. Study done in Ethiopia showed that consuming tea/coffee immediately after meal $(\mathrm{AOR}=3.58)$ and not eating meat frequently (AOR: 2.07) were associated with significant risk of anemia [27]. This low awareness level in conjunction with low practice of three day meal, use of iron rich foods and low 
compliance to iron tablets $(32 \%)$, it's high likely that the study participants are at higher risks of anemia. But in other side of the fact shows that almost $50 \%$ of IDA can be prevented by iron supplementation [16]. Also, regarding awareness on sign and symptoms of IDA, body weakness (fatigue) and shortness of breath was mostly, but still majority did not mention the listed manifestations in advance. This will greatly impede the health care seeking behaviors of mothers by early detection of minor symptoms. This in turn greatly advance the stage of anemia and its adverse pregnant and neonatal outcomes [12].

In this study most of the participants agree and strongly agreed on use of family planning and consuming of iron tablets in order to prevent IDA. It is advised that pregnant women should be supplemented with iron and folic acid for a period of six months with aim to reduce anemia and neural tube defects. In addition, it is well known that birth spacing practice by mother prevents anemia [1, 5]. Similarly, almost greater than half of mother reported that they strongly recommend iron supplementation, family planning for the prevention of IDA [25, 28], which is similar finding with the responses of pregnant mothers in this study. Study done on 400 admitted pregnant women [29] only $45.3 \%$ of participants had used iron supplements during pregnancy, which is higher in our study. Despite the universal recommendation to use iron tablet during recommendation, in our study only $32 \%$ had reported that they regularly took an iron folic acid tablet for prevention or treatment of anemia. While, relatively higher adherence to Iron tablet use of $62 \%$ was reported by $79.4 \%$ of participants have had regular meal which is three times in a day. Still, there is a great geographical variation in the practice of IDA prevention strategies.

In a study conducted in Ethiopia regarding knowledge and prevention practices, $57.3 \%$ and $50 \%$ of pregnant women had a good knowledge ad good attitude respectively [30]. Generally $61 \%$ (95\% CI $=52.6 \%$ to $69.5 \%$ ) of pregnant women had a good knowledge on prevention methods of IDA. More than half, $52.3 \%(95 \% \mathrm{CI}=43.7 \%$ to $61.0 \%)$ had a favorable attitude towards prevention of IDA. While majority of pregnant women, $58.6 \%(95 \% \mathrm{CI}=50.1 \%$ to $67.1 \%)$ had poor adherence to prevention practice of IDA. Even if the results are comparable with other studies [14, 23, 30], the level of knowledge, attitude and practices towards IDA prevention were not satisfactory. In that it still needs great effort by hospitals and the government at large to improve their awareness and practice. As the role of husbands is tremendously improving the health care plan of women, husbands need to be part of the ANC service. Thus, there are tremendous factors that aggravate and made pregnant at risks of anemia in addition to the physiological vulnerability. These behavioral and other factors need to be addressed in the country specific targets for making the Sustainable Development goals in reality in the near future and decreasing anemia by half in the coming 2025 [6].

\subsection{Socio-demographic characteristics of the participants}

Out of the total 128 pregnant women, majority 39 (30.5\%) found under age category of 23-27 years and $107(83.6 \%)$ were married. A total of $50(39.1 \%)$, attended their education at level of diploma and above, with $59(46.1 \%)$ working in governmental institution. Regarding family size, 78 (60.9\%) have two family members, with the majority, $106(82.8 \%)$ of them live in urban, Socio-demographic characteristics of pregnant women attending ante-natal care is shown in Table 1.

Table 1. Socio-demographic characteristics of pregnant women attending ante-natal care

\begin{tabular}{cccc}
\hline Variables & Options & Frequency & Percentage \\
\hline & $18-22$ & 38 & 29.7 \\
Age categories in years & $23-27$ & 39 & 30.5 \\
& $28-32$ & 33 & 25.7 \\
& $33-37$ & 13 & 10.2 \\
Marital status & $38-42$ & 2 & 1.6 \\
& $43-47$ & 3 & 2.3 \\
& Single & 3 & 2.3 \\
Educational Status & Married & 107 & 83.6 \\
& Divorced & 15 & 11.7 \\
& Widowed & 3 & 2.3 \\
Occupational status & Primary school & 28 & 21.9 \\
& Secondary school & 50 & 39.1 \\
& Diploma and above & 50 & 39.1 \\
& Farmer & 13 & 10.2 \\
Number of families & Governmental & 59 & 46.1 \\
& Private & 34 & 26.6 \\
& House wife & 22 & 17.2 \\
Family monthly income (ETB) & 2 & 78 & 60.9 \\
1 ETB = $\$ 28.34$ & 3 & 43 & 33.6 \\
& $\geq 3$ & 7 & 5.5 \\
& $1000-1500$ & 27 & 21.1 \\
& $1500-2500$ & 42 & 32.8 \\
& $\geq 2500$ & 59 & 46.1 \\
& Urban & 106 & 82.8 \\
& Rural & 22 & 17.2 \\
\hline
\end{tabular}

Pregnant mothers' knowledge, attitude and practice towards preventions of iron deficiency... (Abdu Oumer) 


\subsection{Maternal characteristics}

Regarding age at first marriage, about 65 (50.8\%) of pregnant women married at age between 16-20 years. About, $65(50.8 \%)$ gave their first birth at age of 18-22 years. A majority, $103(80.5 \%)$ of the respondents did not suffer from health related problem during the first birth. Almost half of them were their initial visit to the hospital as can be seen in Table 2 .

Table 2. Maternal related characteristics of pregnant women attending antenatal care at hospitals

\begin{tabular}{cccc}
\hline Variables & Options & Frequency & Percentage \\
\hline Age at first & $16-20$ & 65 & 50.8 \\
marriage in Years & $21-25$ & 33 & 25.8 \\
& $26-30$ & 26 & 20.3 \\
& $\geq 31$ & 4 & 3.1 \\
Age in Years & $18-22$ & 65 & 50.8 \\
& $23-27$ & 41 & 32 \\
& $28-32$ & 22 & 16.4 \\
Number of & $\geq 33$ & 1 & 0.8 \\
pregnancy & 1 & 66 & 51.6 \\
(Gravidity) & 2 & 42 & 32.8 \\
& 3 & 18 & 14.1 \\
Years of child & $<3$ Years & 2 & 1.6 \\
spacing & $3-4$ Years & 11 & 39.8 \\
& No child ever & 66 & 8.6 \\
Stage of pregnancy & $1^{\text {st }}$ trimester & 50 & 31.6 \\
& $2^{\text {nd }}$ trimester & 50 & 39.1 \\
Do you suffering & $3^{\text {rd }}$ trimester & 28 & 21.9 \\
from health problem & Yes & 25 & 19.5 \\
Number visit to the & No & 103 & 80.5 \\
health institution & $1^{\text {st }}$ time & 60 & 46.9 \\
& $2^{\text {nd }}$ time & 43 & 33.6 \\
\hline & $3^{\text {rd }}$ time & 25 & 19.5 \\
\hline
\end{tabular}

\subsection{Knowledge on iron deficiency anemia}

Out of the total, $113(88.3 \%)$ of pregnant mothers have ever heard about IDA, in which health professionals were main source of information. About 40 (31.3\%) of pregnant mothers correctly defined the main cause of anemia as iron deficiency. While only small proportion, 18 (14.1\%) of respondents identified some common symptoms of IDA namely general body weakness, dizziness or fainting, poor appetite and shortness of breathing as main sign and symptom of anemia. On knowledge related to prevention of anemia. Majority, 75 (58.6\%) of respondents knew how anemia can be prevented. About one third, 40 (31.3\%) of mother knew that anemia can be prevented by healthy and balanced nutrition as shown in Table 3 .

Generally $61 \%$ (61\% (95\% CI: $52.6 \%$ to $69.5 \%)$ of pregnant women had a good knowledge on prevention methods of IDA. While $39 \%$ of pregnant women had low knowledge score towards prevention of IDA. (Those who score above the mean after coding all correct options as 1 and the other as 0), as shown in Figure 1.

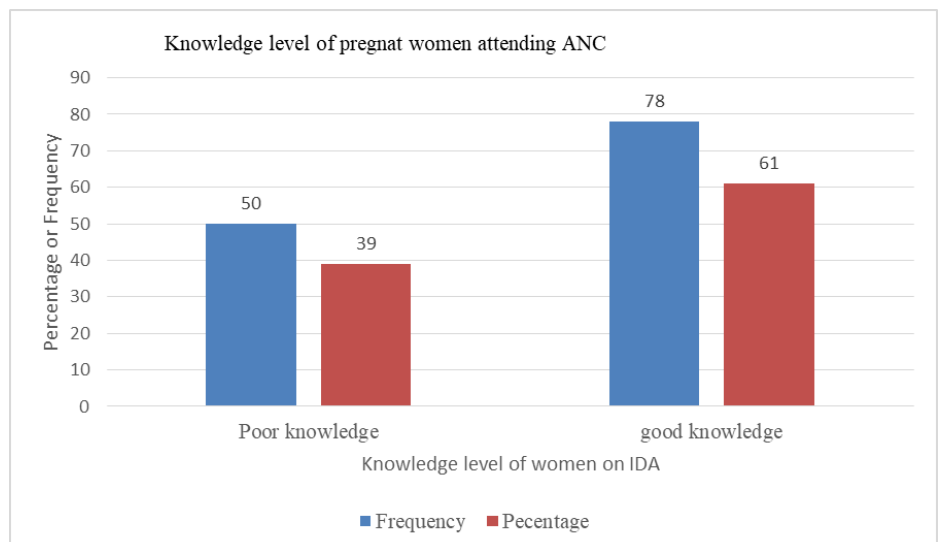

Figure 1. Overall knowledge score of pregnant mothers on IDA in Ethiopia, 2018.

Int. J. Public Health Sci. Vol. 8, No. 2, June 2019: 202 - 210 
Table 3. Knowledge of mothers on prevention of IDA among pregnant women attending ANC

\begin{tabular}{|c|c|c|c|}
\hline \multicolumn{2}{|c|}{ Variables } & \multirow{2}{*}{$\frac{\text { Frequency }}{113}$} & \multirow{2}{*}{$\frac{\text { Percentage }}{88.3}$} \\
\hline Exolound f IDA & Yes & & \\
\hline Ever neard or iDA & No & 15 & 11.7 \\
\hline \multirow{4}{*}{ Causes of anemia } & Poor nutrition & 33 & 25.8 \\
\hline & Iron deficiency & 40 & 31.3 \\
\hline & Low hemoglobin & 7 & 5.5 \\
\hline & I don't know & 48 & 37.5 \\
\hline \multirow{7}{*}{ Sign and symptom of anemia } & shortness of breathing & 14 & 10.9 \\
\hline & Exceptional fatigue & 12 & 9.4 \\
\hline & General body weakness & 18 & 14.1 \\
\hline & Poor appetite & 15 & 11.7 \\
\hline & Dizziness or fainting & 18 & 14.1 \\
\hline & All can be observed & 3 & 2.3 \\
\hline & I don't know & 48 & 37.5 \\
\hline \multirow{4}{*}{ Causes of IDA } & Poor nutrition & 45 & 35.2 \\
\hline & Bleeding during pregnancy & 26 & 20.3 \\
\hline & Multiple pregnancy & 3 & 2.3 \\
\hline & All listed above & 6 & 4.7 \\
\hline \multirow{3}{*}{ Awareness on Prevention of IDA } & I don't know & 48 & 37.5 \\
\hline & Yes & 75 & 58.6 \\
\hline & No & 53 & 41.4 \\
\hline \multirow{4}{*}{ Ways to Prevent IDA } & By good nutrition & 40 & 31.3 \\
\hline & Using Iron supplement & 25 & 19.5 \\
\hline & Drinking or Eating fruits & 7 & 5.5 \\
\hline & All listed above & 3 & 2.3 \\
\hline \multirow{3}{*}{$\begin{array}{l}\text { Drinking tea, coffee and milk can cause } \\
\text { anemia }\end{array}$} & I don't know & 53 & 41.4 \\
\hline & Yes & 39 & 30.5 \\
\hline & No & 89 & 69.5 \\
\hline \multirow{2}{*}{ Spacing child can prevent anemia } & Yes & 78 & 60.9 \\
\hline & No & 50 & 39.1 \\
\hline
\end{tabular}

\subsection{Attitude of pregnant mothers on IDA}

Regarding the mother's attitude towards IDA, majority $52(40.6 \%)$ and $53(41.4 \%)$ were strongly agreed and agree to the statements regarding regular visit have benefits both for the mother and fetus health during pregnancy respectively. The significantly higher proportion of women, about $45(35.2 \%)$ and $35(27.3 \%)$ agreed and strongly agreed that related to drinking of tea, coffee and milk may predispose an individual to IDA respectively. Related to feeding regular meal to prevent anemia and iron supplement, almost half 64 (50\%) agreed and recommend the use of an extra iron tablet (iron supplementation) for pregnant in addition to regular diet to prevent IDA. About $46(35.9 \%)$ and $15(11.7 \%)$ were agreed and strongly agreed, that family planning have greater role in the prevention of anemia. Almost half of pregnant women, agreed that child spacing is important to prevent IDA, Attitude of pregnant mothers towards iron deficiency anemia among ANC attendants is shown in Table 4. More than half, $52.3 \%$ (95\% CI: $43.7 \%$ to $61.0 \%$ ) had favorable attitude towards prevention of IDA. While 67.75 of pregnant women attending ANC had unfavorable attitude towards IDA, attitude level of pregnant women attending ANC on the preventions of Iron deficiency anemia is shown in Figure 2.

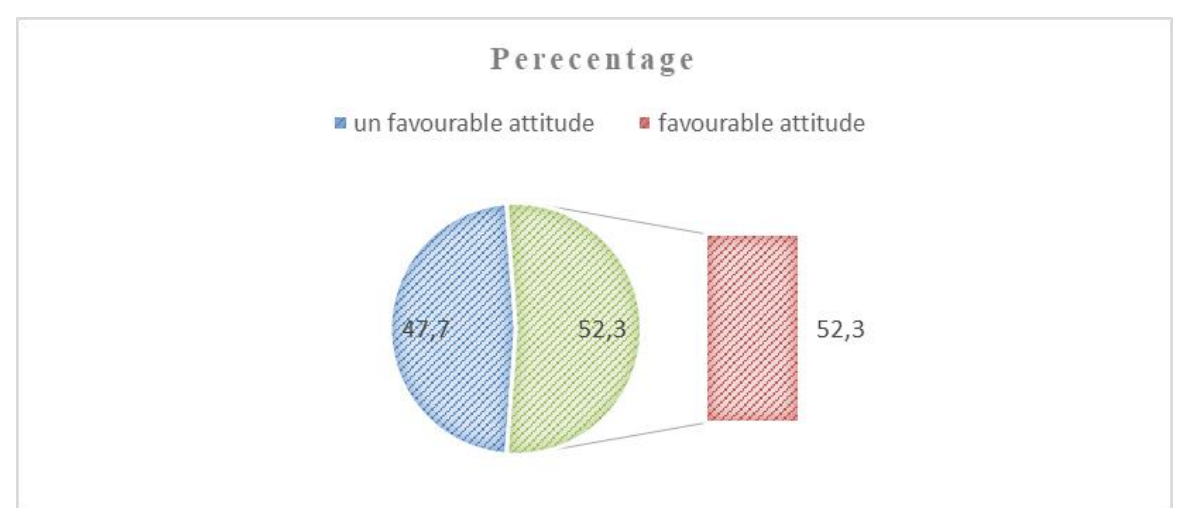

Figure 2. Attitude level of pregnant women attending ANC on the preventions of Iron deficiency anemia

Pregnant mothers' knowledge, attitude and practice towards preventions of iron deficiency... (Abdu Oumer) 
Table 4. Attitude of pregnant mothers towards iron deficiency anemia among ANC attendants

\begin{tabular}{|c|c|c|c|}
\hline & Variables & Frequency & Percentage \\
\hline \multirow{5}{*}{ Regular ANC visit is good to prevent IDA. } & Strongly disagree & 5 & 3.9 \\
\hline & Disagree & 1 & 8 \\
\hline & Neutral & 17 & 13.3 \\
\hline & Agree & 53 & 41.4 \\
\hline & Strongly agree & 52 & 40.6 \\
\hline \multirow{3}{*}{$\begin{array}{l}\text { Iron supplement can affect mother and fetus } \\
\text { health? }\end{array}$} & Strongly disagree & 1 & .8 \\
\hline & Agree & 45 & 35.2 \\
\hline & Neutral & 47 & 36.7 \\
\hline \multirow{5}{*}{$\begin{array}{l}\text { Drinking coffee, tea or milk can affect iron } \\
\text { absorption }\end{array}$} & Strongly agree & 35 & 27.3 \\
\hline & Disagree & 10 & 7.8 \\
\hline & Agree & 37 & 28.9 \\
\hline & Neutral & 70 & 54.7 \\
\hline & Strongly agree & 11 & 8.6 \\
\hline \multirow{4}{*}{ Iron supplements can prevent IDA } & Strongly disagree & 3 & 2.3 \\
\hline & Disagree & 2 & 1.6 \\
\hline & Agree & 50 & 39.1 \\
\hline & Neutral & 52 & 40.6 \\
\hline \multirow{5}{*}{$\begin{array}{l}\text { Regular meals or feeding can prevent } \\
\text { anemia }\end{array}$} & Strongly agree & 21 & 16.4 \\
\hline & Strongly disagree & 1 & 0.8 \\
\hline & Disagree & 2 & 1.6 \\
\hline & Agree & 64 & 50.0 \\
\hline & Neutral & 48 & 37.5 \\
\hline \multirow{5}{*}{$\begin{array}{l}\text { Pregnant women should consume Iron } \\
\text { tablets in spite of healthy diet }\end{array}$} & Strongly agree & 13 & 10.2 \\
\hline & Strongly disagree & 4 & 3.1 \\
\hline & Disagree & 10 & 7.8 \\
\hline & Agree & 46 & 35.9 \\
\hline & Neutral & 53 & 41.4 \\
\hline \multirow{6}{*}{$\begin{array}{l}\text { Promotion of family planning methods for } \\
\text { spacing with prevent anemia }\end{array}$} & Strongly agree & 15 & 11.7 \\
\hline & Strongly disagree & 1 & 0.8 \\
\hline & Disagree & 2 & 1.6 \\
\hline & Agree & 60 & 46.9 \\
\hline & Neutral & 54 & 42.2 \\
\hline & Strongly agree & 11 & 8.6 \\
\hline \multirow{4}{*}{ Spacing child can prevent anemia } & Strongly disagree & 8 & 6.3 \\
\hline & Disagree & 0 & 0 \\
\hline & Agree & 54 & 42.2 \\
\hline & Neutral & 51 & 39.8 \\
\hline \multirow{6}{*}{$\begin{array}{l}\text { Any pregnant women can be affected by } \\
\text { anemia }\end{array}$} & Strongly agree & 15 & 11.7 \\
\hline & Strongly disagree & 4 & 3.1 \\
\hline & Disagree & 9 & 7.0 \\
\hline & Agree & 53 & 41.4 \\
\hline & Neutral & 49 & 38.3 \\
\hline & Strongly agree & 13 & 10.2 \\
\hline
\end{tabular}

\subsection{Iron deficiency anemia prevention practices}

Regarding IDA prevention practice of pregnant mothers, majority 68 (53.1\%) reported that they did not drink tea, coffee and milk along with their meal. While, $87(68 \%)$ of pregnant women did not take an iron tablet (Iron supplementation) regularly and $76(59.4 \%)$ reported that they take regular feeding three times per day. On the other hand, $62(48.4 \%)$ had a habit of Eating red meat. Overall, one third $41(32 \%)$ were found to be anemic $(\mathrm{Hgb}<11 \mathrm{mg} / \mathrm{dl})$. While the more than half of pregnant women, $58.6 \%$ (95\% CI: $50.1 \%$ to $67.1 \%)$ had a poor adherence to prevention practice of IDA, while $41.4 \%$ of ANC attending pregnant women had a good adherence to prevention practice of IDA as shown in Table 5.

The mean knowledge, attitude and practice score of women was $5.4(\mathrm{SD}=3.7), 32.8(\mathrm{SD}=5.4)$ and $3.4(\mathrm{SD}=0.71)$ respectively. The higher knowledge score was positively correlated with attitude score $(\mathrm{r}=0.75, \mathrm{p}<0.001)$. Similarly, higher attitude is associated with increased practice towards prevention of IDA $(\mathrm{r}=0.55, \mathrm{p}<0.001)$. Rather, there is relatively moderate correlation between the mother knowledge and practice of IDA $(r=0.45, p<0.001)$. The mean practice score of rural mother was significantly lower than urban $(\mathrm{F}=12.478 \mathrm{p}=0.01)$. Higher knowledge score, favorable attitude and age were positive predictors of good nutritional practices while family size is inversely related with it, shows the IDA prevention practice of Pregnant mother against Residence (urban versus rural) is shown in Table 6. 
Table 5. Practice of pregnant mothers on prevention of iron deficiency anemia among ANC ante-natal care in Eastern Ethiopia, 2018.

\begin{tabular}{cccc}
\hline Variables & Options & Frequency & Percentage \\
\hline Have you drink tea, coffee and milk with meal? & Yes & 60 & 46.9 \\
Have you used regular iron Tablets? & No & 68 & 53.1 \\
Have you use three regular meals? & Yes & 41 & 32.0 \\
No & 87 & 68.0 \\
pregnancy? & Yes & 76 & 59.4 \\
Have you taken Folic acid supplements in current & No & 52 & 40.6 \\
Yes & 76 & 59.4 \\
Do you have the habit of Eating red meat, liver, & No & 52 & 40.6 \\
Yes & 62 & 48.4 \\
Do you include fiber rich food frequently? & No & 66 & 51.6 \\
Do you include green leafy vegetable in your diet & Yes & 72 & 56.3 \\
every day? & No & 56 & 43.8 \\
Overall IDA practice level & No & 75 & 58.6 \\
IDA prevention practice & Poor & 75 & 41.4 \\
\hline
\end{tabular}

Table 6. Shows the IDA prevention practice of pregnant mother against residence (urban versus rural)

\begin{tabular}{|c|c|c|c|c|c|c|}
\hline & & Sum of Squares & df & Mean Square & $\mathrm{F}$ & Sig. \\
\hline \multirow{4}{*}{ Practicescore * Residence } & Between Groups & 5.767 & 1 & 5.767 & 12.478 & .001 \\
\hline & Within Groups & 58.233 & 126 & .462 & & \\
\hline & \multicolumn{2}{|c|}{ Linear Regression output } & & & & \\
\hline & B (coefficient) & Se (standard error of $\beta$ ) & & $P$ value & & \\
\hline Knowledge score & 0.085 & 0.015 & & 0.0001 & & \\
\hline Attitude score & 0.073 & 0.010 & & 0.0001 & & \\
\hline Age in year & 0.028 & 0.011 & & 0.01 & & \\
\hline Family & $0-.118$ & 0.105 & & 0.264 & & \\
\hline
\end{tabular}

\section{CONCLUSION}

Knowledge, attitude and practice of pregnant women on preventions of IDA are not satisfactory. Thus poor practice towards prevention of IDA are the main contributing factor for high burden of anemia. Thus, it is advised to have focused, simple, easy to understand and customer friendly counseling service at ANC facilities. It should specifically focus on symptoms of anemia, causes, what makes pregnancy at risk, how to prevent IDA among pregnant. This program should involve males/husbands for sustained impact. The need for adherence counselling and follow up on Iron supplement should be focused by health professionals.

\section{ACKNOWLEDGEMENTS}

We are delighted to thank our study participants (pregnant women) and our students for their valuable contributions for this research.

\section{ABBREVIATIONS}

ANC: Ante Natal Care: A/COR: adjusted/Crude Odds ratio: CI: Confidence Interval: IDA: Iron deficiency anemia: r: correlation coefficient: WHO: World health Organization, UNICEF: United Nations Children Education Fund

\section{REFERENCES}

1]. World Health organization (WHO), Haemoglobin concentrations for the diagnosis of anemia and assessment of severity VMNIS Vitamin and Mineral Nutrition Information System, Editor 2011, WHO: Geneva. p. 2-5.

[2]. Khusun, H., et al., World Health Organization Hemoglobin Cut-Off Points for the Detection of Anemia Are Valid for an Indonesian Population. The Journal of Nutrition, 1999. 129(9): p. 1669-1674.

[3]. WHO, Micronutrient Deficiencies: Prevention and Control Guidelines, World Health Organization, 2015, World Health Organization: Geneva, Switzerland. 
[4]. Lim SS, V.T. and Flaxman AD et al., A comparative risk assessment of burden of disease and injury attributable to 67 risk factors and risk factor clusters in 21 regions, 1990-2010: a systematic analysis for the Global Burden of Disease Study 2010 The Lancet, 2012. 380: p. 2224-2260.

[5]. Noronha JA., et al., Anemia in pregnancy and challenges. Journal of South Asian Federation of Obstetrics and Gynecology, 4(1): 64-70. 2012.

[6]. World Health organization (WHO), WHA Global Nutrition Targets 2025: Anaemia Policy Brief, Nutrition, Editor 2011: Geneva.

[7]. World Health Organization (WHO) and Food and Agriculture Organization of the United Nations (FAO), Driving commitment for nutrition within the UN Decade of Action on Nutrition: policy brief. Geneva: World Health Organization; (WHO/NMH/NHD/17.11)., Nutrition, Editor 2018. p. 5-20.

[8]. Endang, et al., Global Nutrition Report Action and accountability in Global Nutrition Report2014. p. 20-40.

[9]. Bhutta, Z., et al., Evidence-based interventions for improvement of maternal and child nutrition: what can be done and at what cost? Maternal and Child Nutrition, 2013. 2: p. 1-15.

[10]. The lancet, Maternal and Child Nutrition Executive Summary of The Lancet Maternal and Child Nutrition Series: Executive summary. The Lancet., 2013: p. 2-5.

[11]. Tay, K., E. Agboli, and W. Walana, Malaria and anemia in pregnant and non-pregnant women of child-bearing age at the University Hospital, Kumasi, Ghana. Open Journal of Medical Microbiology, 2013(3): p. 193-200.

[12]. Chang, S., et al., Effect of Iron Deficiency Anemia in Pregnancy on Child Mental Development in Rural China. Pediatrics, 2013. 131(3): p. e755-e763.

[13]. Jack F., Agostino D., and Sununtnasuk, Nutrition technical brief: A simple method for making a rapid, initial assessment of the consumption and distribution of iron-folic acid supplements among pregnant women in developing Countries, U.S. Partnerships, Editor 2014.

[14]. Guedenon KM, et al., Knowledge, attitude and practice of the mothers with anemia of children under five years old in the peadiatric department at Sylvanus Olympio teaching hospital in Lomé. Tunis Med., 2016. 94(1): p. 46-53.

[15]. Mohammed MA, A.J., Bushra AW, Aljadhey HS. Medications use among pregnant women in Ethiopia: A cross sectional study. Journal of Applied Pharmaceutical Science, 2013; 3 (04): 116-123.

[16]. World Health organization (WHO), The Global prevalence of anemia in 2011, Nutrition, Editor 2015, World Health Organization: Geneva.

[17. EDHS, Ethiopia Mini Demographic and Health Survey in Ethiopia Demographic and Health Survey I. international, Editor 2014, Central Statistical Agency Addis Ababa, Ethiopia p. 53-58.

[18]. Lealem Gedefaw, et al., Anemia and Associated Factors Among Pregnant Women Attending Antenatal Care Clinic in Wolayita Sodo Town, Southern Ethiopia. Ethiop J Health Sci., 2015 25(2): p. 155-162.

[19]. Gebremedhin S, Enquselassie F, and Umeta M, Prevalence and correlates of maternal anemia in rural Sidama, Southern Ethiopia. African journal of reproductive health, 2014. 18(1): p. 44-53.

[20]. Jufar AH and Zewde T, Prevalence of anemia among pregnant women attending antenatal care at Tikur Anbessa specialized hospital, Addis Ababa Ethiopia. Journal of Hematology \& Thromboembolic Diseases., 2014. 2(125).

[21]. Lebso M, Anato A, and Loha E, Prevalence of anemia and associated factors among pregnant women in Southern Ethiopia: A community based cross-sectional study. PloS one, 2017. 12(12).

[22]. Harari Region Statistics, Harari Regional statistics: A population projection from census 2007, 2015: Harar. p. 05-17.

[23]. Maj Sivapriya S. and Laxmipriya P., Study to Assess the Knowledge and Practices Regarding Prevention of Anaemia among Antenatal Women Attending a Tertiary Level Hospital in Pune, International Journal of Science and Research (IJSR), 2015. 4 (3).

[24]. Gawde SR, B.S., Patel TC. Drug utilization pattern in pregnant women attending antenatal out Patient Department of a tertiary care hospital. British journal of pharmaceutical research, 2013; 3(1): 2231-2919.

[25]. Amani Waleed M., Iron Deficiency Anemia among Pregnant Women in Nablus District; Prevalence, Knowledge, Attitude and Practices, at An-Najah National University, Nablus, Palestine, . 2007.

[26]. Fredanna AD., Cormack M., and Judy CD, Assessment of Anemia Knowledge, Attitudes and Behaviors Among Pregnant Women in Sierra Leone. 2012. 44(2).

[27]. Weldekidan, F., et al., Determinants of Anemia among Pregnant Women Attending Antenatal Clinic in Public Health Facilities at Durame Town: Unmatched Case Control Study. Anemia, 2018. 2018: p. 8.

[28]. Hussain T and Shu LY, Awareness of iron deficiency anemia among women of reproductive age in Hubei province, China. Asian J Med Sci 2010. 1: p. 12-13.

[29]. Alina, D.P., et al., Nutritional knowledge as a determinant of vitamin and mineral supplementation during pregnancy. BMC Public Health. 2013. 13(1105).

[30]. Keneni Berhanu, D., Jayanthigopal, and D. Dereje Bayissa, Assessment of Knowledge and Practice Towards Prevention of Anemia Among Pregnant Women Attending Antenatal Care at Government Hospitals in West Shoa Zone, Ethiopia Journal of Health, Medicine and Nursing 2018 50(31 ): p. 31-40. 